\title{
In memoriam Professor Dr. Georg Benz (14. Juli 1926 - 15. Juni 2021)
}

\author{
Daniel Burckhardt ${ }^{1}$ \\ 1 Naturhistorisches Museum, Augustinergasse 2, 4001 Basel, Switzerland \\ http://zoobank.org/A9DD9E46-0F76-4C95-9E01-7E84EE6FB4DF \\ Corresponding author: Daniel Burckhardt (daniel.burckhardt@bs.ch)
}

Academic editor: Thibault Lachat • Received 30 August 2021 • Accepted 4 November 2021 • Published 22 November 2021

Kurz vor seinem 95. Geburtstag ist Professor Dr. Georg A. Benz am 15. Juni 2021 nach einem langen, erfüllten Leben verstorben. Seit 1991 war er Ehrenmitglied der SEG in Anerkennung seiner Verdienste um unsere Gesellschaft, der er seit 1960 als Mitglied angehörte. Im Vorstand war er von 1977-1982 Bibliothekar, von 1982-1991 Redaktor der Mitteilungen, von 1986-1988 Präsident und von 1989-1991 Vizepräsident. Während dieser Zeit war er auch Gastgeber mehrerer Jahresversammlungen sowie Organisator der ersten gemeinsamen Tagung mit der Deutschen Gesellschaft für allgemeine und angewandte Entomologie und der Österreichischen Entomologischen Gesellschaft 1981 in St. Gallen.

Georg Benz stammte aus Marbach SG, wo er auch aufwuchs. Sein Zoologie-Studium absolvierte er an der Universität Zürich. Dort erwarb er 1951 ausserdem das Diplom für das höhere Lehramt. Anschliessend arbeitete er über Insektenphysiologie bei Prof. V.B. Wiggleworth in Cambridge, UK. Von 1952-1956 war er Doktorand und Assistent von Prof. E. Hadorn an der Universität Zürich. Auf seine Promovierung mit der Dissertation über zwei Letalfaktoren von Drosophila melanogaster folgten drei Jahre als Forschungsassistent bei Prof. F.E. Lehmann am Zoologischen Institut der Universität Bern. Eine im Auftrag des Entomologischen Instituts der ETH absolvierte Ausbildung in Insektenpathologie führte ihn 1959-1960 nach Nordamerika (Insect Pathology Research Institute in Sault Ste. Marie, Ontario, Kanada und Department of Insect Pathology der University of California, Berkeley, bei Prof. E.A. Steinhaus). Seine dort geführten Untersuchungen über den Nukleinsäure Stoffwechsel gesunder und viröser Fichtenblattwespen bildeten die Basis für seine spätere Habilitationsarbeit.

Georg Benz trat 1960 als Mitarbeiter des Lärchenwickler-Projektes, in dem er die Pathologie und Physiologie betreute, ins Entomologische Institut der ETH Zürich ein. Mit dem 1963 erhaltenen Lehrauftrag für Insektenpathologie begann seine erfolgreiche Dozenten- laufbahn. Es folgten die Habilitation an der Abteilung $\mathrm{X}$ der ETH für Pathologie und Physiologie der Insekten (1966), die Ernennung zum ausserordentlichen (1968) und zum ordentlichen (1972) Professor für Entomologie. Von 1972 bis zu seiner Emeritierung am 1. Oktober 1993 leitete er das Entomologische Institut (von 19721980 zusammen mit V. Delucchi). In seiner 30-jährigen Lehrtätigkeit an der ETH deckte er ein grosses und vielseitiges Angebot von Vorlesungen, Kursen und Exkursionen, die bei den Studenten besonders beliebt waren, $a b$. Seine Vorlesungen an den Abteilungen für Naturwissenschaften, Forstwirtschaft, Landwirtschaft, Pharmazie und Umweltwissenschaften reichten von Allgemeiner Biologie und Entomologie über Insektenpathologie, Insektenphysiologie und Insektenökophysiologie zu Forstentomologie. Seine pädagogische Ausbildung und sein gutes Gedächtnis halfen ihm, die Entomologie einem grossen Kreis von Studierenden näher zu bringen. Ähnlich vielfältig waren auch die Themen der vielen von ihm betreuten Diplomarbeiten und der 40 Doktorarbeiten. Neben dem Unterricht an der ETH hielt er zudem Gastvorlesungen an verschiedenen Universitäten in der Schweiz, Deutschland, Österreich und den USA. Als Forscher hinterlässt Georg Benz ein beachtliches Werk von 175 wissenschaftlichen Publikationen, das sein breites Interesse und seine grosse Kompetenz in verschiedenen Fachgebieten der Biologie reflektiert. Seine gute Beobachtungsgabe und der Sinn für relevante Fragen prägen seine Arbeiten. Eine Liste seiner Publikationen, die auch diverse Beiträge für mehrere internationale Standardwerke enthält, findet sich in einer anlässlich seines 80. Geburtstags publizierten Schrift (Burckhardt und Keller 2006). Neben Unterricht und Forschung war er zudem Redaktor und Fachberater mehrerer wissenschaftlicher Zeitschriften und Redaktor von drei Büchern. Ebenso war er Mitglied diverser Gremien: FAOExperte in der Türkei, in Ruanda und Burundi, Council Member der ICIPE-Foundation (Stockholm), Mitglied 


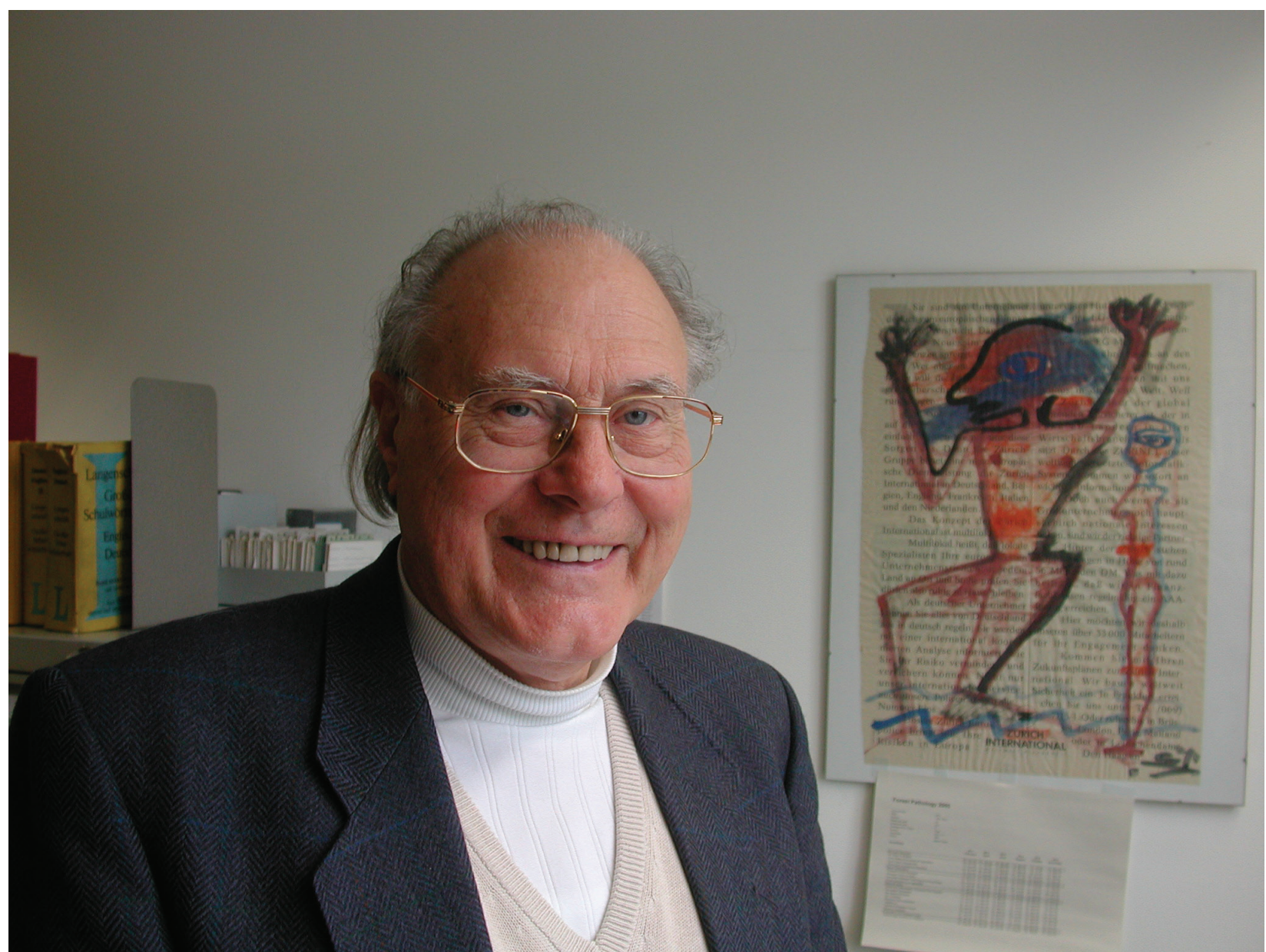

Abbildung 1. Georg Benz am 25. Februar 2005 in der ETH Zürich (Foto Ottmar Holdenrieder).

der OILB, in der er die Arbeitsgruppe «Virus Control of Orchard Tortricides» leitete und 1993 die Tagung der Arbeitsgruppe «Insect Pathogens and Insect Parasitic Nematodes» organisierte, sowie langjähriger Präsident der Forschungskommission der Schweizerischen Naturforschenden Gesellschaft (heute Akademie der Naturwissenschaften Schweiz).

Auch privat interessierte sich Georg Benz immer für die Zusammenhänge in der Natur, sei es auf Spaziergängen oder in seinem geliebten Garten, belegt durch die in seinem «Gartentagebuch» festgehaltenen Beobachtungen, das er seit seiner Emeritierung bis 2015 geführt hat. Neben den Naturwissenschaften war er an Politik interes- siert und der Kunst zugetan. So war er ein guter Zeichner und Sänger, hörte gerne Musik und las gerne.

Das Interesse und die Faszination für die Natur begleiteten ihn durch das ganze Leben bis ins hohe Alter. Als enthusiastischen und engagierten Entomologen werden wir Georg Benz in Erinnerung behalten.

\section{Literatur}

Burckhardt D, Keller S (2006) Zum 80.Geburtstag von Professor Dr. Georg Benz. Mitteilungen der Schweizerischen Entomologischen Gesellschaft 79: 149-165. https//doi.org/10.5169/seals-402917 